ORNL/SPR-2015/254

\title{
Task 4 - EMI/RFI Issues Potentially Impacting Electromagnetic Compatibility of I\&C Systems (NRCHQ6014D0015)
}

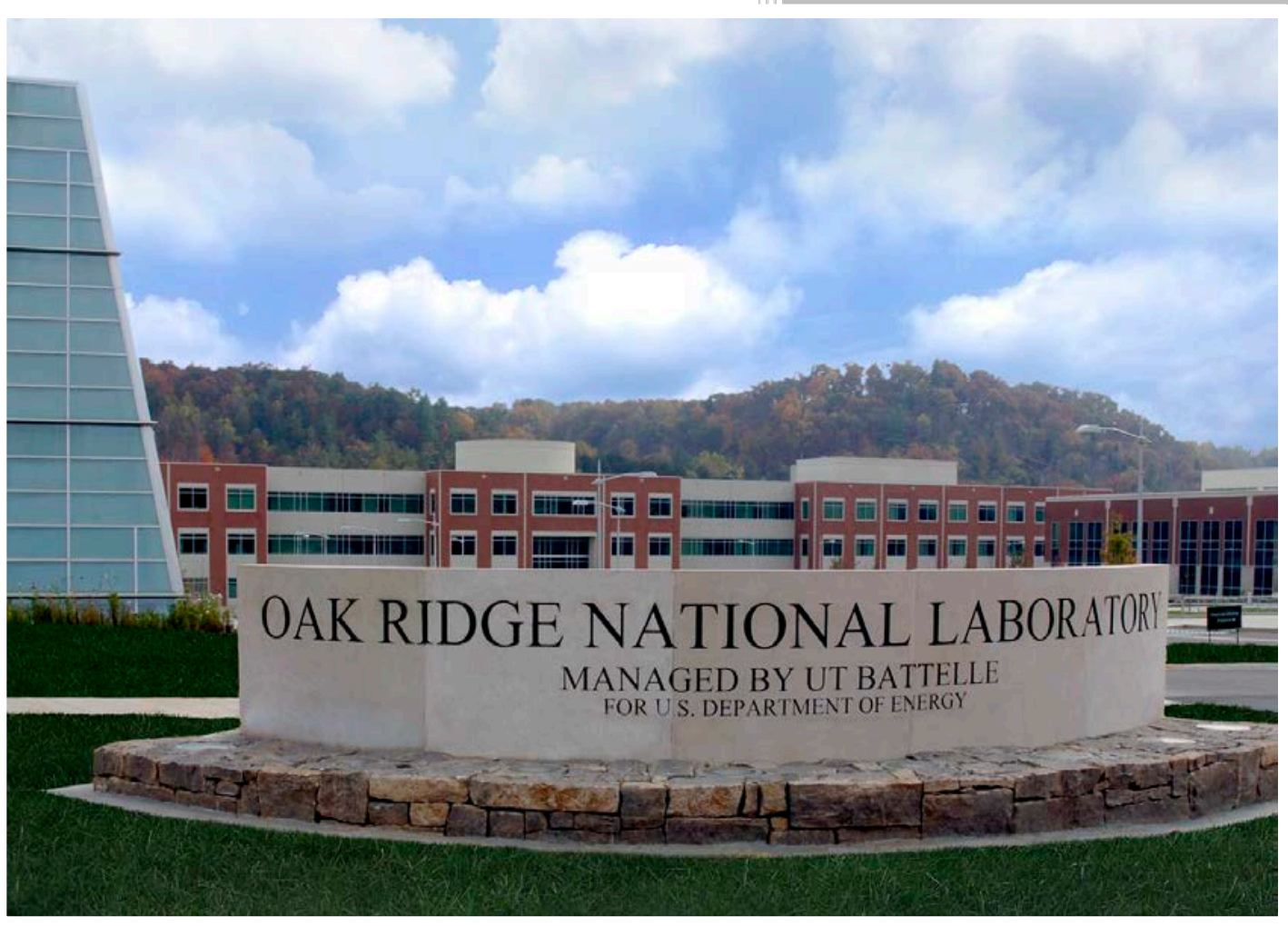

Richard T. Wood

Paul D. Ewing

Approved for public release. Distribution is unlimited.

May 2015 


\title{
DOCUMENT AVAILABILITY
}

Reports produced after January 1, 1996, are generally available free via US Department of Energy (DOE) SciTech Connect.

\section{Website http://www.osti.gov/scitech/}

Reports produced before January 1, 1996, may be purchased by members of the public from the following source:

\author{
National Technical Information Service \\ 5285 Port Royal Road \\ Springfield, VA 22161 \\ Telephone 703-605-6000 (1-800-553-6847) \\ TDD 703-487-4639 \\ Fax 703-605-6900 \\ E-mail info@ntis.gov \\ Website http://www.ntis.gov/help/ordermethods.aspx
}

Reports are available to DOE employees, DOE contractors, Energy Technology Data Exchange representatives, and International Nuclear Information System representatives from the following source:

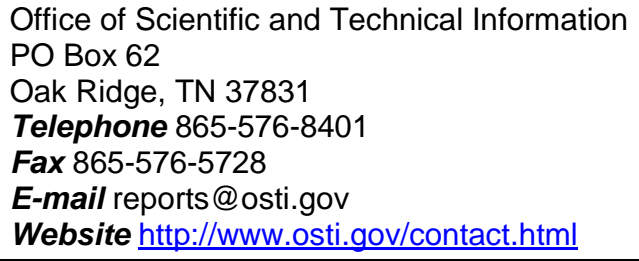

This report was prepared as an account of work sponsored by an agency of the United States Government. Neither the United States Government nor any agency thereof, nor any of their employees, makes any warranty, express or implied, or assumes any legal liability or responsibility for the accuracy, completeness, or usefulness of any information, apparatus, product, or process disclosed, or represents that its use would not infringe privately owned rights. Reference herein to any specific commercial product, process, or service by trade name, trademark, manufacturer, or otherwise, does not necessarily constitute or imply its endorsement, recommendation, or favoring by the United States Government or any agency thereof. The views and opinions of authors expressed herein do not necessarily state or reflect those of the United States Government or any agency thereof. 
Reactor and Nuclear Systems Division Electrical and Electronics Systems Research Division

\title{
Task 4 - EMI/RFI Issues Potentially Impacting Electromagnetic Compatibility of I\&C Systems (NRCHQ6014D0015)
}

\author{
Richard T. Wood \\ Paul D. Ewing
}

Date Published: May 2015

Prepared by

OAK RIDGE NATIONAL LABORATORY

Oak Ridge, Tennessee 37831-6283

managed by

UT-BATTELLE, LLC

for the

US DEPARTMENT OF ENERGY

under contract DE-AC05-00OR22725 



\section{CONTENTS}

\section{Page}

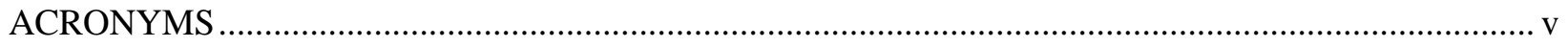

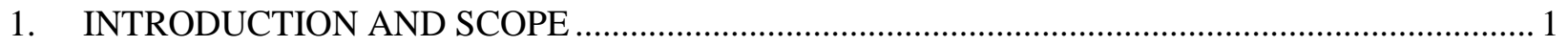

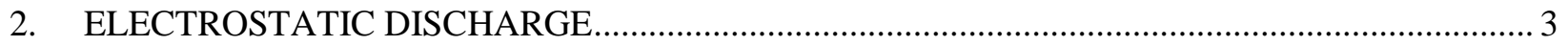

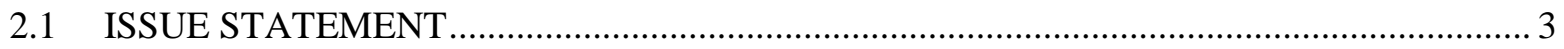

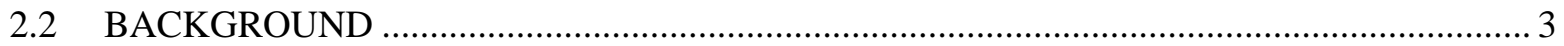

2.3 BASIS FOR EXISTING REGULATORY POSITION ….................................................. 4

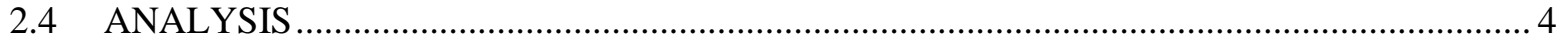

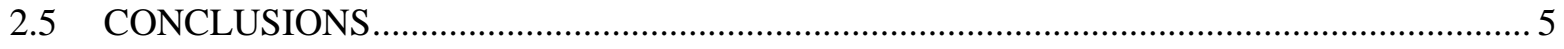

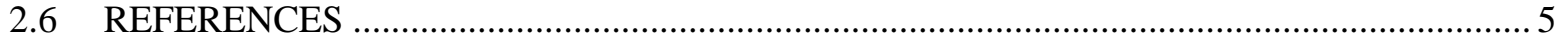

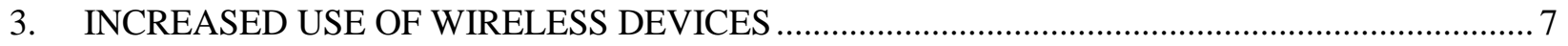

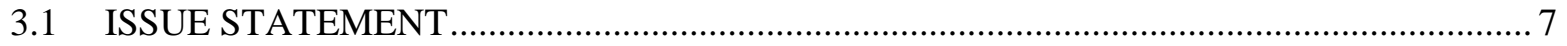

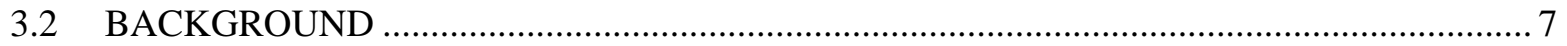

3.3 BASIS FOR EXISTING REGULATORY POSITION …............................................... 7

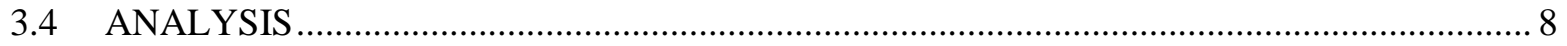

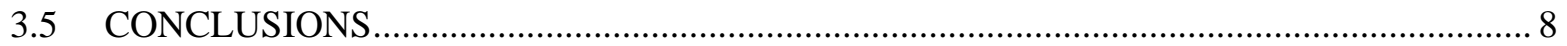

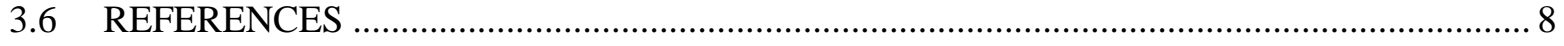





\section{ACRONYMS}

$\begin{array}{ll}\text { CCF } & \text { common-cause failure } \\ \text { EMC } & \text { electromagnetic compatibility } \\ \text { EMI } & \text { Electromagnetic interference } \\ \text { EPRI } & \text { Electric Power Research Institute } \\ \text { ESD } & \text { hectrostatic discharge } \\ \text { HMI } & \text { instrumentation and control } \\ \text { I\&C } & \text { International Electrotechnical Commission } \\ \text { IEC } & \text { Military Standard } \\ \text { MIL-STD } & \text { U.S. Nuclear Regulatory Commission } \\ \text { NRC } & \text { Oak Ridge National Laboratory } \\ \text { ORNL } & \text { radio-frequency interference } \\ \text { RFI } & \text { Regulatory Guide } \\ \text { RG } & \text { standard } \\ \text { Std } & \end{array}$





\section{INTRODUCTION AND SCOPE}

The U.S. Nuclear Regulatory Commission's (NRC’s) regulations in Part 50, “Domestic Licensing of Production and Utilization Facilities," of Title 10 of the Code of Federal Regulations (10 CFR Part 50) state that structures, systems, and components important to safety in a nuclear power plant are to be designed to accommodate the effects of environmental conditions (i.e., remain functional under all postulated service conditions) and that design control measures such as testing are to be used to check the adequacy of design. Regulatory Guide (RG) 1.180 was developed to provide guidance to licensees and applicants on methods acceptable to the NRC staff for complying with the NRC's regulations on design, installation, and testing practices for addressing the effects of electromagnetic and radio-frequency interference (EMI/RFI) and power surges on safety-related instrumentation and control (I\&C) systems. The first revision of RG 1.180 was issued in January 2000 and a second revision was issued in October 2003*.

The second revision differed from the first revision in endorsing Military Standard (MIL-STD)-461E and the International Electrotechnical Commission (IEC) Standard (Std) 61000 series of EMI/RFI test methods, extending the guidance to cover signal line testing, incorporating frequency ranges where portable communications devices are experiencing increasing use, and relaxing the operating envelopes (test levels) when experience and confirmatory research warranted. It also offered exemptions from specific test criteria based on technical considerations such as plant conditions and the intended location of the safety-related I\&C equipment.

Since the last revision, new requirements have been identified, associated RGs have been created and updated, and additional industry guidance has been developed. Additionally, the operational environment has changed with the increase in wireless communication technology for both personal (smartphone) and industrial (remote I\&C) purposes. Also, specific concerns and issues with testing methods and methodologies have been identified that must be addressed. Further, most of the standards that serve as the basis for the RG have been revised.

Therefore, the NRC's Office of Regulatory Research has contracted with Oak Ridge National Laboratory (ORNL) to incorporate new information and resolve the identified issues under NRC-HQ-60-14-D-0015, "Update to RG 1.180, Revision 2, Guidelines for Evaluating Electromagnetic and Radio-Frequency Interference in Safety-Related Instrumentation and Control Systems.” The ultimate goal of this project is to provide NRC the technical basis for developing and publishing a new revision of the RG.

The focus of Task 4 was for ORNL to identify and address any new or additional EMI/RFI issues that could potentially impact the EMC of I\&C systems. More specifically, ORNL was to evaluate the impact of any new issue on safety equipment in their local environments and then determine whether the issues should be included and discussed in the revision to RG 1.180 that is currently under way.

The two additional issues that are discussed in this brief letter report are the following:

- The impacts of electrostatic discharge (ESD) on safety equipment; and

- The impacts of increased usage of wireless devices in nuclear power plants.

\footnotetext{
* This manuscript has been authored by UT-Battelle, LLC under Contract No. DE-AC05-00OR22725 with the U.S. Department of Energy. The United States Government retains and the publisher, by accepting the article for publication, acknowledges that the United States Government retains a non-exclusive, paid-up, irrevocable, world-wide license to publish or reproduce the published form of this manuscript, or allow others to do so, for United States Government purposes. The Department of Energy will provide public access to these results of federally sponsored research in accordance with the DOE Public Access Plan (http://energy.gov/downloads/doe-public-access-plan).
} 
Section 2 of this report discusses and presents findings and conclusions on the ESD issue while Section 3 of the report focuses similarly on the increased usage of wireless devices. Both sections are structured essentially in the same manner first defining the issue, providing relevant background information, presenting the basis for the current regulatory position, discussing the results from an assessment of the impact from a common-cause failure (CCF) perspective on safety systems, and then presenting conclusions as to any guidance that may need to be included in the update to RG 1.180 relative to ESD and increased usage of wireless devices. References pertinent to each topic areas are included in each, respective section. 


\section{ELECTROSTATIC DISCHARGE}

ESD is the sudden transfer of charge between two objects at differing electrostatic potential. ESD can be a destructive phenomenon that can damage sensitive electronics. An ESD event can result in immediate failure or create a latent fault. Immediate failure is characterized by permanent damage resulting in loss of functionality. A latent fault consists of damage or degradation that shortens the life of the equipment and may lead to premature, unpredictable failure.

\subsection{ISSUE STATEMENT}

RG 1.180, Revision 1, [1] does not currently address ESD immunity testing in its EMC guidance. However, the Electric Power Research Institute (EPRI) EMC guide (EPRI TR-102323 [2]) and the IEC Std for nuclear power plant EMC testing (IEC 62003 [3]) do specify ESD testing. The issue to be resolved is whether ESD testing should be included in the revised regulatory guidance.

\subsection{BACKGROUND}

IEC defines ESD as the transfer of electric charge between bodies of different electrostatic potential in proximity or through direct contact. A static electric charge may be created in an object (body) by triboelectric charging or electrostatic induction. The EPRI EMC guide describes this electrostatic potential as either a "bound charge on an insulator" or "an induced charge on a conductor."

Triboelectric charging is contact electrification in which materials become electrically charged as they exchange electrons during contact. The triboelectric effect is generally associated with friction or rubbing between objects. However, the effect is actually the result of temporary adhesion accompanied by electron redistribution that equalizes electrochemical potential during the instantaneous chemical bond. Examples of the charge generated by the triboelectric effect include:

a) walking across a carpet $\rightarrow 1,500$ to $35,000 \mathrm{~V}$,

b) walking over untreated vinyl floor $\rightarrow 250$ to $12,000 \mathrm{~V}$,

c) worker at a bench $\rightarrow 700$ to $6,000 \mathrm{~V}$,

d) vinyl envelope used for work instructions $\rightarrow 600$ to $7,000 \mathrm{~V}$, and

e) picking up a common plastic bag from a bench $\rightarrow 1,200$ to $20,000 \mathrm{~V}$.

Electrostatic induction occurs when an electrically charged object is moved in close proximity to an uncharged, electrically-conducting object. The presence of the charged object creates an electrostatic field that causes the surface charge of the neutral object to redistribute. If the neutral, conducting object is insulated, the electrostatic potential is retained until a conductive path is established to permit discharge.

Discharge can occurs either with direct contact (i.e., establishment of a conductive path) or arcing (i.e., formation of an ionized conductive channel in air). For the latter effect, the arc (or spark) is triggered when the electrostatic field strength exceeds the dielectric field strength of air. This process is called dielectric breakdown. Essentially, the air abruptly becomes an electrical conductor and the electrostatic charge is discharged.

Electric and magnetic field variations are produced by an ESD event. The penetration of these fields into equipment is somewhat limited. Electric fields will not penetrate conductive surfaces while magnetic fields will not penetrate ferrous materials. The magnetic fields can indirectly induce EMI in conductor loops inside equipment or in cables near the discharge point. However, the fields generated by ESD fall off rapidly (e.g., by a factor of 10 for far-field emissions and by a factor of 100 to 1,000 for near-field emissions). Thus, the effect of either direct or indirect discharges is highly localized. 
ESD may result in high peak currents (e.g., greater than $10 \mathrm{~A}$ ) of very short time duration (e.g., less than 50 nanoseconds). The maximum level for an ESD event is dependent on conditions that affect the dielectric breakdown process of air and the dissipation of charge through air ionization. Thus, atmospheric pressure, temperature and humidity are key environmental parameters. Humidity is an especially significant factor in determining the ESD level. High humidity promotes more rapid dissipation of charge than under dry conditions.

\subsection{BASIS FOR EXISTING REGULATORY POSITION}

Review guidance in NUREG-0800, Chapter 7, [4] identifies ESD along with EMI as environmental effects that warrant treatment during qualification. However, RG 1.180, Rev. 1, and its predecessor [5] do not include testing guidance for immunity to ESD. The basis for not including ESD in the existing and prior version of the regulatory guide arises from the understanding that ESD is not a common-cause failure phenomenon in the strictest interpretation of the terminology. Indeed, as noted above, ESD is a localized event. Thus, given the separation practices employed in implementing redundant safety channels and spatially distributed safety interfaces, it is generally not feasible for a single event to cause multiple effects leading to a simultaneous failure of multiple safety divisions. Essentially, the technical basis for RG 1.180 considered that other design criteria specified for safety systems mitigate vulnerability of safety functions to effects resulting from an ESD event. In fact, the EPRI EMC guide concurs with this interpretation, stating that an ESD event "does not represent a common mode failure for a safety system.”

\subsection{ANALYSIS}

As noted, an ESD event does not constitute an immediate CCF threat to safety systems. However, it is also noted that multiple ESD events can occur over a period of time, especially under low humidity conditions. Since ESD can result in degradation that gives rise to latent faults, it is possible for multiple events over a time interval between safety demands or in-service tests to result in essentially concurrent failure of more than one safety division. Consequently, the phenomenon of ESD should be considered as a potential source of CCF.

Additionally, it should be recognized that the regulatory guidance on EMC applies to all safety-related I\&C systems and components, which are not all implemented in redundant divisions. Therefore, the additional protection provided by redundancy with safety systems should not be the prevailing consideration in assessing potential threats. It is feasible for failure of a safety-related component to lead to immediate safety relevant effects.

A cursory search of the Licensee Event Report database found a small number of events over the past three decades that are attributed to ESD. As an example, a plant trip occurred at the Donald C. Cook Nuclear Generating Station on March 11, 1997, as a result of ESD [6]. Specifically, the controller for a feedwater regulating valve failed when a reactor operator touched it to switch it to manual for mandated surveillance. Consequently, the valve close, leading to a trip based on steam generator low level coincident with a steam flow/feed flow mismatch. Thus, it is seen that ESD can result in safety significant failures.

In the prevailing international standard on ESD testing (IEC 61000-4-2 [7]), the highest bounding levels for industrial environments is specified as $\pm 8 \mathrm{kV}$ for direct contact discharge and $\pm 15 \mathrm{kV}$ for indirect air discharge. These conditions correspond to environments with very low humidity and extensive use of synthetic fabrics (which promote generation of higher electrostatic charges by personnel). The energy transfer for ESD is a function of the discharge current as well as the electrostatic voltage existing prior to the discharge. However, at higher voltages, the discharge current typically is less than proportional to the pre-discharge voltage. Thus, susceptibility requirements are established in terms of discharge current amplitudes. The IEC Std specifies the required characteristics of the discharge current from test equipment (i.e., the ESD generator). Based on these considerations, the highest level (i.e., level 4) 
identified for test limits in the standard serve as a conservative bound for industrial environments, which would include facilities like power plants.

Since the primary concern is to ensure that safety functions do not fail, regulatory guidance should address susceptibility of safety-related equipment to electrostatic stress that could effect key interfaces or compromise the health of multiple redundant components, e.g., through latent effects (undetected in the interval between in-service tests) resulting from multiple events. Since administrative controls (e.g., proper grounding, limitations on concurrent access of redundant equipment) are imposed as part of a plant's maintenance program, the appropriate focus for regulatory guidance should be properly centered on discharges that may occur during operation. Consequently, test points should be based on accessibility during normal operation. For example, human-machine interface (HMI) components such as panel displays, keyboards and control/input devices are touched frequently during operational activities and, thus, should be tested. Specifically, touch points of all HMI equipment that are electrically isolated from ground should be tested. Cables that are accessible during normal operations or are in close proximity to HMI touch points should be tested at their entry point to equipment or cabinets.

\subsection{CONCLUSIONS}

There are several touch points for I\&C systems and their displays in the control and equipment rooms of a nuclear power plant. Additionally, low humidity conditions can exacerbate the build up and intensity of electrostatic charge and lead to multiple significant discharge events over time. Finally, there is a notable potential that latent faults in I\&C systems and their displays can be introduced through discharge events. Consequently, there is a potential safety effect of ESD through the damage and prospective failure of sensitive electronic equipment. As a result, it is concluded that ESD testing should be included as an element of the regulatory guidance on EMC. It is recommended that a regulatory position be added to RG 1.180 to endorse the current standard test method (IEC 61000-4-2) for ESD, to specify an appropriate test envelope ( $\pm 8 \mathrm{kV}$ contact discharge and $\pm 15 \mathrm{kV}$ air discharge), and to define the test points (any HMI touch points isolated from ground and directly accessible cable entry points).

\subsection{REFERENCES}

1. U.S. Nuclear Regulatory Commission, Guidelines for Evaluating Electromagnetic and Radio Frequency Interference in Safety-Related Instrumentation and Control Systems, Regulatory Guide 1.180, Revision 1, October 2003INPO 11-005 Addendum, Lessons Learned from the Nuclear Accident at the Fukushima Dai-ichi Nuclear Power Station, August 2012.

2. Electric Power Research Institute, Guidelines for Electromagnetic Interference Testing in Power Plants, Revision 4 to TR-102323, Report Number 3002000528, Palo Alto, CA, December 2013.

3. International Electrotechnical Commission Standard 62003, "Nuclear power plants - Instrumentation and control important to safety - Requirements for electromagnetic compatibility testing," Geneva, Switzerland, March 2009.

4. Nuclear Regulatory Commission, Standard Review Plan, Chapter 7, "Instrumentation and Control," NUREG-0800, Revision 5, 2007.

5. U.S. Nuclear Regulatory Commission, Guidelines for Evaluating Electromagnetic and Radio Frequency Interference in Safety-Related Instrumentation and Control Systems, Regulatory Guide 1.180, Revision 0, January 2000.

6. Nuclear Regulatory Commission, Regulatory Information Distribution System, LER 97-001-00, Accession \# 9704160170.

7. International Electrotechnical Commission Standard 61000, Part 4-2, "Testing and measurement techniques - Electrostatic discharge immunity test,” Geneva, Switzerland, December 2008. 



\section{INCREASED USE OF WIRELESS DEVICES}

\subsection{ISSUE STATEMENT}

Wireless communications are not currently used in safety-related systems in nuclear facilities, but are being used for nonsafety-related and business applications. Consequently, from a regulatory point of view, these wireless systems are just another source of incidental, man-made EMI and should be treated accordingly. At the time of the earlier issuance of RG-1.180, wireless systems were limited to operational radios and pagers; however, their application has now been expanded to network-based communications spanning diverse applications, as well as cellular communication devices.

\subsection{BACKGROUND}

An increasing number of wireless systems are being deployed in nuclear facilities for nonsafety-related applications [1], including some I\&C types: field bus data, distributed control systems, voice and visual communications, plant process monitoring, computer access points, mobile work orders, mobile drawings and procedures, and personal radiation detection devices. Most of these applications require some type of wireless network access (cellular, personal area, local area, wide area, mesh, ad-hoc, etc.) that is based on emerging wireless standards. These include wireless fidelity (WiFi) (IEEE 802.11), Bluetooth (IEEE 802.15.1), ZigBee (IEEE 802.15.4), WirelessHART, and ISA-100.11a. There are also some process control vendors developing proprietary wireless systems to support their specific needs (e.g., OneWireless by Honeywell, Smart Wireless by Emerson, and ION by Aprion). Most of these wireless systems operate in the unlicensed FCC frequency bands $(900 \mathrm{MHz}, 2.4 \mathrm{GHz}$, and $5.9 \mathrm{GHz}$ ) or in the cellular telephone bands (800 MHz and $1.9 \mathrm{GHz}$ ).

\subsection{BASIS FOR EXISTING REGULATORY POSITION}

The technical basis for the operating envelopes for radiated emissions from $2 \mathrm{MHz}$ to $1 \mathrm{GHz}$ and radiated susceptibility from $30 \mathrm{MHz}$ to $1 \mathrm{GHz}$ is detailed in NUREG/CR-6431. The technical basis begins with the MIL-STD envelopes corresponding to the electromagnetic environment for military ground facilities, which were judged to be comparable to that of nuclear power plants based on general layout and equipment type considerations. Plant emissions data were then used to confirm the adequacy of the MILSTD operating envelopes or adjust them to account for the plant emissions data reported in NUREG/CR6436 and EPRI TR-102323. It should be noted that there was no plant data above $1 \mathrm{GHz}$ because there were no devices operating in that frequency range. A subsequent update was made in Rev. 1 of RG-1.180 to address the operating envelopes above $1 \mathrm{GHz}$. This update is documented in Position 6 of the regulatory guide. The envelope for susceptibility testing is also based on MIL-STD operating envelopes. Specifically, the guide extends the $10 \mathrm{~V} / \mathrm{m}$ envelope across the $1 \mathrm{GHz}$ to $10 \mathrm{GHz}$ frequency range.

In addition, the regulatory guide specified that exclusion zones be established through administrative controls to control the local electromagnetic environment and ensure that portable or temporary transmitters do not introduce emissions that challenge the general operating envelopes. Thus, the exclusion zones prohibit the activation of portable EMI/RFI emitters (e.g., welders and transceivers) in areas where safety-related I\&C systems are installed. An exclusion zone is defined as the minimum distance permitted between the point of equipment installation and where portable EMI/RFI emitters are allowed to be activated. The size of an exclusion zone depends on the effective radiated power and antenna gain of the portable EMI/RFI emitters. To establish the size of an exclusion zone, an $8 \mathrm{~dB}$ difference between the susceptibility operating envelope and the allowed emissions level should be maintained. For the radiated susceptibility operating envelope of $10 \mathrm{~V} / \mathrm{m}(140 \mathrm{~dB} \mu \mathrm{V} / \mathrm{m})$, the size of the exclusion zones are set such that the radiated electric fields emanating from the portable EMI/RFI emitters are limited to $4 \mathrm{~V} / \mathrm{m}(132 \mathrm{~dB} \mu \mathrm{V} / \mathrm{m})$ in the vicinity of safety-related I\&C systems. The minimum 
distance of the exclusion zone can calculated using the free space propagation equation (provided in RG 1.180).

\subsection{ANALYSIS}

Present day observations show that there are multiple wireless systems in nuclear facilities operating in the unlicensed FCC frequency bands. This would seem to indicate that there are now numerous additional sources of EMI between $1 \mathrm{GHz}$ and $10 \mathrm{GHz}$ that should be accounted for during testing. The frequency ranges and operating envelopes of the RE102 and RS103 tests were adjusted to $10 \mathrm{GHz}$ in Position 6 of the current regulatory guide, so coverage for wireless systems is already in place. What remains is to ensure that emissions from the wireless systems do not invalidate the current radiated emissions operating envelope. Because of their unlicensed nature, these wireless systems are low powered $(<1 \mathrm{~W})$ and an increase in them should not pose a significant escalation in the noise levels of the overall electromagnetic environment. Without additional plant data, it is logical that the emissions levels already incorporated for the RE102 test over this range be maintained. However, it would be advisable for periodic measurements to be taken in a sampling of plants to affirm that the operating envelopes are not challenged by new implementations or modifications and thus remain valid. It is also logical that the susceptibility operating envelope $(10 \mathrm{~V} / \mathrm{m})$ for the frequency range between $1 \mathrm{GHz}$ and $10 \mathrm{GHz}$ be maintained. This would of course include that the administrative controls related to exclusion zones.

\subsection{CONCLUSIONS}

Since the RG currently provides guidance on operating envelopes for the high-frequency radiated testing and the implementation of exclusion zones, the means of ensuring that wireless devices do not cause emission levels in excess of the $10 \mathrm{~V} / \mathrm{m}$ susceptibility envelope (with margin included) are in place. Consequently the potential impact of wireless systems was adequately anticipated in Rev. 1 of RG-1.180 and no change is necessary.

\subsection{REFERENCES}

1. IEC 62918TR, Ed. 1, Selection and Use of Wireless Devices to be Integrated in NPP Important for Safety Systems, International Electrotechnical Commission, July 2014. 